\title{
On the Arbitrariness and Complexity in Thermoeconomics due to Waste Cost and Supplementary Firing Treatment
}

\author{
Marcelo A. Barone,,${ }^{1, * \#}$ Rodrigo G. dos Santos,,${ }^{1,2, \#}$ Pedro R. de Faria, ${ }^{1,3, \#}$ Raphael A. Lorenzoni, ${ }^{1}$ Atílio B. Lourenço ${ }^{1}$ \\ and José Joaquim C. S. Santos ${ }^{1}$
}

\begin{abstract}
Cost allocation, optimization, and diagnosis are the main application fields of thermoeconomics. Cost allocation allows evaluation of the plant cost formation process. For plants containing dissipative equipment, the use of total exergy flows in the conventional productive diagrams is not able to isolate these components. The physical exergy disaggregation, despite increasing the complexity, allows the treatment of dissipative equipment and residues. Nevertheless, conventional productive diagrams based on productive flows and fictitious units to connect the subsystems, may not take into account the physical connections existing in the system flowsheet, making the cost formation process arbitrary. The comprehensive diagram uses both flow types, physical and productive, and the subsystems are interconnected according to the physical flows of the flowsheet. This work aims to demonstrate that the combination of exergy disaggregation and a comprehensive diagram avoids arbitrariness. The application of localized exergy disaggregation in the comprehensive diagram reduces the complexity. A gas turbine cogeneration system is chosen as one application example. Productive and comprehensive diagrams are compared with total and localized disaggregation and a systematic procedure to treat waste and dissipative equipment is presented. The reduction of complexity is performed through localized disaggregation and the arbitrariness related to the productive diagram is evaluated.
\end{abstract}

Keywords: Arbitrariness; Localized disaggregation; Waste cost allocation; Dissipative component; Thermoeconomic diagram.

Received: 12 October 2021; Revised: 25 November 2021; Accepted: 27 November 2021.

Article type: Research article.

\section{Introduction}

In the $1960 \mathrm{~s}$, a new science emerged, thermoeconomics, which unites the disciplines of economics and thermodynamics. It provides tools to solve problems in complex energy systems based on physical criteria, for instance, a rational cost assessment of the internal flows and final products of a plant. Thermoeconomics presents three main areas of applications: cost allocation, optimization, and diagnosis. ${ }^{[1-3]}$ Nevertheless, cost allocation is the field of application that defines and evaluates the consistency of the cost formation process, mainly in cost allocation to cogeneration plant products.

To perform the term economic analysis is necessary to use the same thermodynamic magnitude to allow the comparison of different types of flows on equal bases. Exergy, according

\footnotetext{
${ }^{1}$ Federal University of Espírito Santo - UFES, Vitória, Brazil.

${ }^{2}$ Federal Institute of Espírito Santo - IFES, Vitória, Brazil.

${ }^{3}$ Federal Institute of Espírito Santo - IFES, Cariacica, Brazil.

\# These authors contributed to this work equally.

*E-mail: mabacz@gmail.com (M. Barone)
}

to many thermoeconomic researchers, ${ }^{[4-6]}$ is the best thermodynamic magnitude to be associated with cost, as it contains information from the first and second laws of thermodynamics, qualifies energy stream, and identifies irreversibilities.

The productive purpose definition of dissipative equipment using total exergy flows only (E Model) is compromised since it is impossible to clearly define the fuel and product of this equipment. ${ }^{[7]}$ The regular solution is to merge them with other production equipment. However, there is a loss of information about the cost formation process in these devices.

One of the solutions is physical exergy disaggregation, which allows for determining the waste $\cos ^{[8]}$ and dissipative equipment isolation. Some systems need to be considered through the exergy disaggregation, such as thermal, mechanical, or chemical terms, or even fictitious flows (negentropy), ${ }^{[9]}$ despite increasing the complexity to elaborate the cost equations due to the growth of the flow number to be analyzed..$^{[10,11]}$ The physical exergy disaggregation into thermal and mechanical terms (ET \& EM Model) improves the accuracy of the result in thermoeconomics. ${ }^{[12]}$ Nonetheless, 
this disaggregation does not offer any advantage in waste cost allocation and dissipative equipment isolation, as it does not define a product to this equipment, e.g., the intercooler or condenser. Moreover, according to this paper, ${ }^{[12]}$ it can contain arbitrariness in the calculation of the separate terms, especially using working fluids that can change phases in the process.

Frangopoulos et al. ${ }^{[13]}$ presented an elegant solution to deal with dissipative components (condenser). The author used total exergy flows join up with negentropy (E\&S Model). However, the negentropy is a fictitious flow. ${ }^{[8,9]}$ This proposal allows us to define the fuel and product of the condensers and intercoolers. However, it has already been shown that this solution presents uncommon values of energetic unit costs, i.e., lower than the unit. ${ }^{[8,10,11,14,15]}$ To achieve consistent values of energetic unit costs, Santos et al. ${ }^{[11,14]}$ approached negentropy with a different perspective. The authors proposed it as the entropic term to be used together with enthalpy, both are considered as terms of physical exergy, ${ }^{[16]}$ which allowed isolating the condensers and intercoolers without that uncommon values.

Recently, a proposal to isolate dissipative equipment was presented, which uses the localized physical exergy disaggregation in a convectional productive diagram. ${ }^{[17-19]}$ This technique allows for reducing the complexity involved when compared to the total physical exergy disaggregation since it is applied only to dissipative equipment.

The productive diagrams use the product flows and fictitious units (junctions and bifurcations) to connect the subsystems, thus allowing the cost evaluation of the internal productive flows and the final products. ${ }^{[7,20]}$ The presence of fictitious units can lead to arbitrariness as it is up to the analyst to define the cost formation process. ${ }^{[4]}$ Due to the presence of fictitious components, the productive diagram may not take into account the actual physical connections existing in the system flowsheet. A demonstration of the cost calculation using the productive diagram was carried out. ${ }^{[21]}$ The study gives a physical meaning to the productive flows, thus avoiding the arbitrariness of the fictitious units. The authors show a new diagram, combining physical and productive flows, which is here called a comprehensive diagram.

The comprehensive diagram needs physical and productive flows to build the equations system, hence allowing the cost assessment of both flows. Additionally, the subsystems are interconnected through the actual physical flows presented in the flowsheet, avoiding the arbitrariness present in the productive diagram due to the presence of fictitious components (junctions and bifurcations). The comprehensive diagram was used for diagnosis application, ${ }^{[22-24]}$ and cost allocation using total exergy. ${ }^{[3,21,25-27]}$ None of these works applied the $\mathrm{H} \& \mathrm{~S}$ Model into the comprehensive diagram.

Different from the conventional productive diagrams, the physical and comprehensive diagrams use physical flows to interconnect the subsystems. Nonetheless, the physical flows are not enough to identify the waste formation process. Some works $^{[28-31]}$ agree that the cost of exergy from the waste and the resources used on its respective treatment methods must be distributed among the productive units, and thus to the final products, proportionally to its responsibility for such magnitude. ${ }^{[32]}$ This proportionality is also known as residue cost distribution ratios and can be defined by different methods, i.e., there are no general criteria to define it.

Different thermoeconomic methodologies, ${ }^{[2,29,33,34]}$ in the 1990s, did not explicitly take into account the destination of waste in their cost-formation process. Among the methodologies that work with the physical diagram are the Exergetic Cost Theory (ECT) ${ }^{[2]}$ and Exergoeconomic/AVCO ${ }^{[34]}$ The first established that the waste cost must be allocated to the Heat-Recovery Steam Generator (HRSG), which caused an increase in the heating cost. While in the second, the waste is allocated proportionally to the amount of power and heat produced. For the methodologies that use the productive diagram, thermoeconomic Functional Approach (TFA) ${ }^{[29]}$ and Engineering Functional Analysis (EFA) ${ }^{[33]}$ the waste cost allocation is carried out implicitly and proportionally to the thermal exergy consumed in the production unit that produced the final products. A difference in the EFA methodology is the use of thermal and mechanical exergy in conjunction with the negentropy flow. Since 2000, several methodologies for waste treatment and dissipative equipment isolation were presented. The main proposals are Lazzaretto and Tsatsaronis, ${ }^{[12]}$ Torres et al., ${ }^{[28]}$ Santos et al., ${ }^{[11,14]}$ Seyyedi et al., ${ }^{[30]}$ Agudelo et al., ${ }^{[8]}$ and Lugo Mendes et al.. ${ }^{[31]}$

Lazzaretto and Tsatsaronis ${ }^{[12]}$ proposed that the operating cost of dissipative equipment must be charged directly to the component it serves, while the waste should be charged to the combustion chamber. Torres et al. ${ }^{[28]}$ proposed two cost allocation methodologies, that were compared in a combined cycle. The first option is the waste cost allocated proportionally to the exergy of the flows processed in the dissipative units. The second option uses the entropy generation along the process to allocate it proportionally.

In the $\mathrm{H} \& \mathrm{~S}$ Model, ${ }^{[11,14]}$ the residues cost is allocated to all the remaining units and/or components, firstly and directly by means of the entropic term flows and later using the enthalpic term flows. H \& S Model had already been applied for the residue cost allocation in a gas turbine cogeneration system $^{[10]}$ and the isolation of dissipative components and residues treatment in a combined cycle. ${ }^{[15]}$ It was also applied in a Rankine cycle to isolate the condenser. ${ }^{[35]}$

Seyyedi et al. ${ }^{[30]}$ presented new criteria for cost distribution ratios based on the entropy distributed in the components. This method and ECT Method ${ }^{[2]}$ were applied to a high-temperature gas-cooled reactor coupled with the steam cycle through the heat exchanger ${ }^{[36]}$ and the results have been compared with those obtained by $\mathrm{H} \& \mathrm{~S}$ Model.

Agudelo et $a .^{[8]}$ used a methodology that was an improvement of the cost distribution ratios proposed by Torres et al. ${ }^{[28]}$ Liu et al. ${ }^{[37]}$ applied the methodology developed by Agudelo et al..$^{[8]}$ in two natural gas cogeneration systems to obtain the unit exerts the economic cost of products. 
Lugo-Mendes et al. ${ }^{[31]}$ proposed a cost distribution ratio based on irreversibilities It was applied in the Three-PressureLevel Combined Cycle, and the results were compared with those obtained by Torres et al. ${ }^{[28]}$ (Option 2), Seyyedi et al. ${ }^{[30]}$, and Agudelo et al. ${ }^{[8]}$. This method is an extension of the second option presented by Torres et al. ${ }^{[28]}$

A methodology of reallocating waste cost through the comprehensive diagram ${ }^{[25,26]}$ was presented. ${ }^{[38,39]}$ This method allocated the residue cost in the internal loop of physical flows, instead of directly in the production unit.

Torres et al. ${ }^{[28]}$ reported that the thermoeconomic methodologies do not consider the residue's cost allocation and their formation process in the analysis of the cost allocation, thus it needs to develop new techniques or enhance the existing one's methodologies to include both. The H \& S Model was elaborated thinking in the residue cost allocation and the dissipative equipment isolation, but this model originally is used in the conventional productive diagram. Therefore, it was exposed to arbitrariness due to the fictitious units (junctions and bifurcations).

Given the above, this work seeks a systematization of the cost formation process with less arbitrariness. This work aims to demonstrate that the combination of physical exergy disaggregation ( $\mathrm{H} \& \mathrm{~S}$ Model) with the comprehensive diagram avoids the arbitrariness related to subsystem interconnection, as also the residue cost distribution ratios, and the application of the localized physical exergy disaggregation at the comprehensive diagram to reduce the complexity. For this purpose, a gas turbine cogeneration system, with an intercooler and supplementary firing, is chosen as an application example. The chosen system meets several demands and challenges of the term economic analysis such as the treatment of waste and dissipative equipment isolation (intercooler). Productive and comprehensive diagrams are compared for $\mathrm{E}$ and $\mathrm{H} \& \mathrm{~S}$ Models, the systematic way of $\mathrm{H} \& \mathrm{~S}$ Models in order to allocate the waste cost allocation and dissipative equipment isolation is presented, as well as the residue cost distribution ratios applied to $\mathrm{E}$ Model in the comprehensive diagram. The reduction of complexity by means of localized physical exergy disaggregation is performed and the arbitrariness related to the presence of fictitious units on the productive diagram is evaluated, presenting different options of arrangements.

\section{Thermoeconomic modeling}

The term economic model is described mathematically by a set of equations, which determine the cost formation process of the system. ${ }^{[32]}$ Hence, a thermoeconomic model must be used to determine the external resources allocation for the final products, and consequently, for the assessment of the energetic and the monetary unit cost of both internal flows and final products. A general rule to formulate the cost equations was summarized by Lazzaretto and Tsatsaronis, ${ }^{[12]}$ and Santos et $a l .{ }^{[40]}$ It can be applied in any thermoeconomic model based on productive diagram or physical structure. ${ }^{[41]}$
To obtain the cost equation balances, Eq. (1) is applied in each subsystem of the diagram to calculate the monetary unit cost (c) of each internal flow and final product. The monetary unit cost of a flow is the amount of external monetary unit required to obtain one unit of this flow. In other words, it is a measure of the economic efficiency of the flow production process. $^{[4]}$

$$
\sum\left(c_{\text {out }} \cdot Y_{\text {out }}\right)-\sum\left(c_{\text {in }} \cdot Y_{\text {in }}\right)=Z+c_{f} \cdot Q_{f}
$$

In Eq. (1), the right side is formed by $\mathrm{c}_{\mathrm{f}}$ which represents the external fuel cost per exergy unit (in $\$ / \mathrm{kWh}$ ), $Q_{f}$ is the plant's external exergy consumption (in $\mathrm{kW}$ ), and $Z$ represents the hourly equipment cost (in $\$ / h$ ). In the left side of the equation, the subscript out and in represents the outlet and inlet of the subsystems, $c$ is the monetary unit cost flows, and $Y$ means the generic thermodynamic magnitude (in $\mathrm{kW}$ ), which can be assessed by using any thermodynamic magnitude, such as power $(\mathrm{P})$, total exergy $(\mathrm{E})$, entropic $(\mathrm{S})$, and enthalpic $(\mathrm{H})$ terms, etc

To obtain the energetic unit cost (k) of each flow, Eq. (1) was modified to Eq. (2). Furthermore, the hourly equipment cost must be zero $(Z=0)$, and the monetary unit cost of the external fuel exergy is replaced to energetic unit cost, which is assumed equal to one $\left(\mathrm{k}_{\mathrm{f}}=1.00 \mathrm{~kJ} / \mathrm{kJ}\right)$ when there is no information on the production process of the external fuel. ${ }^{[4]}$

$$
\sum\left(k_{\text {out }} \cdot Y_{\text {out }}\right)-\sum\left(k_{\text {in }} \cdot Y_{\text {in }}\right)=k_{f} \cdot Q_{f}
$$

The energetic unit cost of a flow (in $\mathrm{kJ} / \mathrm{kJ}$ ) is the amount of exergy required to obtain one exergy unit of this flow and it is a measure of the thermodynamic efficiency of the production process generating this flow. ${ }^{[4]}$

The number of internal flows is always greater than the number of cost equations (Eqs. (1) or (2)) when applied to production units or components. Thus, auxiliary equations are needed. For models that present a productive structure through the productive diagram, they use the criterion of equality, which assumes that all productive flows exiting the same subsystem have the same unit cost, because it is exiting the same subsystem with the same resources and irreversibilities, i.e., the productive flows go through the same cost formation process. ${ }^{[2,42,43]}$ To obtain the auxiliary equation for the comprehensive diagram, the fuel and product principles ${ }^{[12]}$ are considered, which is in accordance with the propositions formulated in the ECT for determining costs. ${ }^{[2,44]}$ The product principle enunciates that all productive outlet flows of the same subsystem have the same unit cost. On the other hand, the fuel principle enunciates that a component uses the exergy part of a flow to produce a given product, then the inlet and outlet exergy flows have the same unit cost.

The $\mathrm{E}$ and $\mathrm{H} \& \mathrm{~S}$ Models are the thermoeconomic methodologies applied in this work. The E Model is used in all production equipment, while the $\mathrm{H} \& \mathrm{~S}$ Model is used in the dissipative component only. This combination here is called "Localized physical exergy disaggregation" which was proposed by Santos et al.. ${ }^{[17]}$

The thermoeconomic methodologies can provide different 
cost values when they define different productive structures, that is, the values depend on the definition of fuel and product in the subsystems and also how they are interconnected. ${ }^{[4]}$ According to these recognized authors, ${ }^{[4]}$ cost validation is a key issue in thermoeconomics that has not been properly solved yet. However, the cost validation can be achieved through the physical behavior of the system with thermodynamics, since irreversibility is a physical magnitude that generates the cost.

So, to be coherent with the thermodynamics, each component fuel must be greater than the product (the efficiency is less than $100 \%$ ), and the energetic unit cost of the products in a system must be less than their exergetic unit cost when they are a single product of the system. ${ }^{[11]}$

\section{Case study}

The study of the cogeneration system with a regenerative gas turbine, intercooler, and supplementary firing aims to address cost allocation. The system has two combustion processes, with the supplementary firing not directly influencing the power generation. The presence of dissipative equipment (intercooler) is used to verify the influence of the total or localized exergy disaggregation, as well as to analyze the arbitrariness of the fictitious components. In all assessments, the reference temperature and pressure (dead state) are $25^{\circ} \mathrm{C}$ $(298.15 \mathrm{~K})$ and 1.0132 bar, respectively.

\subsection{Physical Structure}

Figure 1 represents the physical structure of a cogeneration system with a regenerative gas turbine, intercooler, and supplementary firing. The system is composed of eight components: low-pressure air compressor (LC), intercooler (IC), high-pressure air compressor (HC), regenerator (R), combustion chamber (CC), gas turbine (GT), supplementary firing (SF), and recovery boiler (RB). The system produces net power and useful heat as the final products.

The thermodynamic model used is the complete combustion, with pure methane $\left(\mathrm{CH}_{4}\right)$ as a fuel with a lower heating value (LHV) of $50,023 \mathrm{~kJ} / \mathrm{kg}$. The combustion gases are composed of the same elements present in atmospheric air. It should be noted that this gas cycle plant has a combustion chamber and supplementary firing, which implies three different working fluids in the plant cycle, and consequently three different chemical compositions. Table S1 in supplementary information shows the elemental chemical composition of air flows, gases after the combustion chamber (CC Gases), and gases after the supplementary firing (SF Gases).

The gas turbine produces $5478 \mathrm{~kW}$ of mechanical power, of which $1032 \mathrm{~kW}(18.83 \%)$ is used to drive the low-pressure air compressor (LC), $1066 \mathrm{~kW}(19.45 \%)$ is used in the highpressure air compressor (HC), and net mechanical power produced $\left(\mathrm{P}_{\mathrm{N}}\right)$ is $3380 \mathrm{~kW}(61.70 \%)$.

The exergy consumptions in the combustion chamber $\left(\mathrm{Q}_{\mathrm{F} 1}\right)$ and supplementary firing $\left(\mathrm{Q}_{\mathrm{F} 2}\right)$ are $5348 \mathrm{~kW}$ and $333.6 \mathrm{~kW}$, respectively. The useful heat $\left(\mathrm{Q}_{\mathrm{U}}\right)$ on an exergetic basis has the value of $566.2 \mathrm{~kW}$, which is obtained by the difference between the exergy of the saturated steam (flow 11) and the feed water (flow 12). The physical flow parameters of the system (flow, pressure, and temperature) are presented in Table 1.

The enthalpy $(H)$ and entropy $(S)$ properties were calculated using Eqs. (3) and (4), respectively, where $h$ and $s$ are the specific enthalpies and specific entropies, and the subscript ref refers to the reference state. All fluid properties were obtained with the EES software. ${ }^{[45]} \mathrm{A}$ constant term is added to the specific properties obtained by the EES software, to obtain positive property values. The constant term is a delta with a value of 65.6 , in this case.

$$
\begin{aligned}
& H=m \cdot\left(h-h_{\text {ref }}+\text { delta }\right) \\
& S=m \cdot T_{0} \cdot\left(s-s_{\text {ref }}+\text { delta }\right)
\end{aligned}
$$

\subsection{Productive diagram}

Each plant has only one physical structure, which describes the physical relations between the components through physical flows. On the other hand, based on a productive structure, it is possible to develop various productive diagrams, as it depends on the fuel and product definitions, as well as on the distribution of plant resources to the productive units. Therefore, it is an arbitrary procedure, which depends on the analysis and interpretation of the analyst..$^{[9,46-48]}$ Valero et al..$^{[4]}$

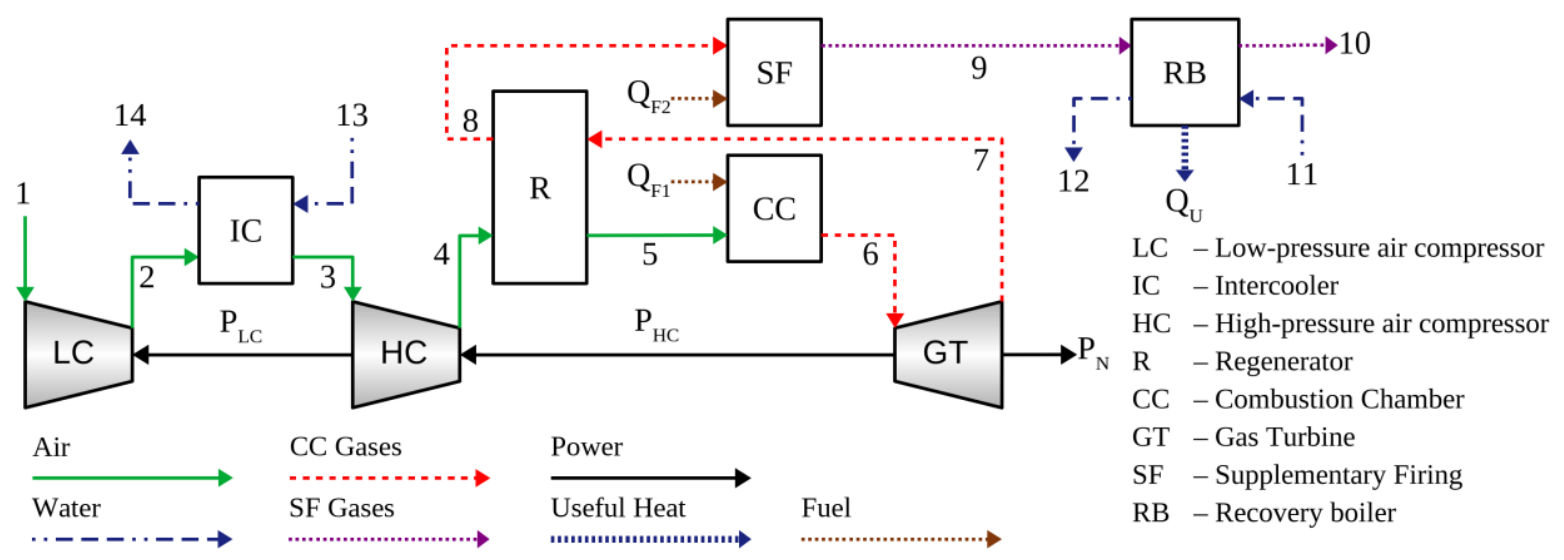

Fig. 1 The cogeneration physical structure. 
Table 1. Parameters of physical flows of the system.

\begin{tabular}{|c|c|c|c|c|c|c|c|c|}
\hline \multicolumn{2}{|c|}{ Physical Flow } & \multirow{2}{*}{$\begin{array}{c}\mathrm{m} \\
(\mathrm{kg} / \mathrm{s})\end{array}$} & \multirow{2}{*}{$\begin{array}{c}\mathrm{T} \\
(\mathrm{K})\end{array}$} & \multirow{2}{*}{$\begin{array}{c}\mathrm{P} \\
\text { (bar) }\end{array}$} & \multirow{2}{*}{$\begin{array}{c}\mathrm{e} \\
(\mathrm{kJ} / \mathrm{kg})\end{array}$} & \multirow{2}{*}{$\begin{array}{c}\mathrm{h} \\
(\mathrm{kJ} / \mathrm{kg})\end{array}$} & \multirow{2}{*}{$\begin{array}{c}\mathrm{s} \\
(\mathrm{kJ} / \mathrm{kg})\end{array}$} & \multirow{2}{*}{$\begin{array}{c}\mathrm{e}^{\mathrm{CH}} \\
(\mathrm{kJ} / \mathrm{kg})\end{array}$} \\
\hline $\mathrm{n}^{\mathrm{o}}$ & Description & & & & & & & \\
\hline 1 & Air & 10.00 & 298.15 & 1.01 & 0.000 & 65.600 & 65.600 & 0.000 \\
\hline 2 & Air & 10.00 & 399.57 & 2.48 & 91.651 & 168.804 & 77.153 & 0.000 \\
\hline 3 & Air & 10.00 & 308.15 & 2.43 & 75.669 & 75.728 & 0.059 & 0.000 \\
\hline 4 & Air & 10.00 & 412.79 & 5.96 & 170.757 & 182.371 & 11.614 & 0.000 \\
\hline 5 & Air & 10.00 & 915.00 & 5.81 & 456.203 & 724.582 & 268.379 & 0.000 \\
\hline 6 & CC Gases & 10.13 & 1435.51 & 5.67 & 939.090 & 1382.457 & 443.367 & 10.849 \\
\hline 7 & CC Gases & 10.13 & 996.98 & 1.05 & 385.189 & 841.641 & 456.452 & 10.849 \\
\hline 8 & CC Gases & 10.13 & 526.13 & 1.03 & 63.706 & 306.388 & 242.683 & 10.849 \\
\hline 9 & SF Gases & 10.15 & 586.67 & 1.01 & 92.617 & 372.702 & 280.086 & 12.276 \\
\hline 10 & SF Gases & 10.15 & 435.37 & 1.01 & 25.619 & 209.525 & 183.906 & 12.276 \\
\hline 11 & Water & 0.62 & 298.15 & 10.00 & 0.903 & 66.435 & 65.532 & - \\
\hline 12 & Saturated Steam & 0.62 & 453.03 & 10.00 & 818.355 & 2737.806 & 1919.452 & - \\
\hline 13 & Water & 22.27 & 298.15 & 1.01 & - & 4.710 & - & - \\
\hline 14 & Water & 22.27 & 308.15 & 1.01 & - & 6.587 & - & - \\
\hline
\end{tabular}

reported that a physical meaning is necessary for the productive flows, to obtain the exergy costs with a physical meaning.

The fictitious units (junction and bifurcation) present in the productive diagram, underline this arbitrariness since the same thermal system can present different arrangements. Therefore, in addition to a physical meaning for productive flows, the proper definition of the productive structure is also a key point of thermoeconomics, ${ }^{[32]}$ which will improve the identification of the origin and the waste formation process, as well as the cost allocation. ${ }^{[28]}$

Given the above, this work analyzes, for each thermoeconomic model, two possible arrangements of the productive diagram in order to compare an allocation of extra exergy added in the supplementary firing (SF). In the first (Arrangement 1), the extra exergy is allocated to the useful power and heat through a single junction-bifurcation. Whereas in the second (Arrangement 2), there are two fictitious units, that separate the fuel exergy and the extra exergy added by supplementary firing (SF). Thus, one of these units is responsible for allocating the extra exergy only to useful heat, while another fictitious unit proportionally distributes the fuel exergy included in the combustion chamber between the power and useful heat.

The productive diagrams (Figs. 2-6), also known as the functional diagram, graphically represent the fuel and product of each unit present in the productive structure. The systems' components are represented through rectangles that are real units or subsystems. In addition, the rhombus and circles are fictitious units called junctions (J) and bifurcations (B), respectively. ${ }^{[49]}$

The product and fuel definitions of productive flows are obtained from the specific working fluid exergy variation. Regarding E Model, once this variation is negative, it is classified as fuel, and the opposite, as a product. ${ }^{[12]}$ According to de Araújo et al..$^{[41]}$ in the H\&S Model, for the enthalpic term and chemical exergy to be positive terms in Eq. (5), the definitions of fuel and product are performed equally to the $\mathrm{E}$ Model. For the entropic term, the behavior is exactly the opposite, i.e., this term has a negative contribution in Eq. (5), thus if there is an increase in specific entropy variation, this will be fuel, otherwise, product.

$$
\begin{aligned}
E_{i: j}= & H_{i: j}-S_{i: j}+E_{i: j}^{C H}=\left(m_{i} h_{i}-m_{j} h_{j}\right) \\
& -T_{0}\left(m_{i} s_{i}-m_{j} s_{j}\right)+\left(m_{i} e_{i}^{C H}-m_{j} e_{j}^{C H}\right)
\end{aligned}
$$

As well as total exergy $\left(E_{\mathrm{i}: \mathrm{j}}\right)$, the enthalpic term $\left(\mathrm{H}_{\mathrm{i}: \mathrm{j}}\right)$, the entropic term $\left(\mathrm{S}_{\mathrm{i}: \mathrm{j}}\right)$, and chemical exergy $\left(\mathrm{E}^{\mathrm{CH}} \mathrm{i}_{\mathrm{i}: \mathrm{j}}\right)$ are variations of the enthalpic, entropic, and chemical terms of exergy between physical states $i$ and $j$, respectively.

Tables 3 and 4 define the productive structure of the system studied for the E model and the H\&S model, both for physical flows and for productive flows.

\subsubsection{E Model}

Figures 2 to 3 show the productive diagrams using E Model. The productive flows present in these diagrams interconnect the productive and fictitious units, and these exergies flows can be represented by the mechanical power $(\mathrm{P})$, the exergy of the useful heat $\left(\mathrm{Q}_{\mathrm{U}}\right)$, or the variation of exergy $\left(\mathrm{E}_{\mathrm{i}: \mathrm{j}}\right)$, that are composed by the variation of two physical flows $\left(E_{i}\right.$ and $\left.E_{j}\right)$, as shown in Eq. (6).

$$
E_{i: j}=E_{i}-E_{j}=e_{i} m_{i}-e_{j} m_{j}
$$

In any energy system, all components can be divided into two groups: productive and dissipative equipment. The former provides resources to the other equipment or generates the final product of the system. While the latter purpose is to eliminate undesirable flows. At the same time, it is equipment in which exergy is destroyed without gaining thermodynamically directly from the same component. ${ }^{[12,28]}$ 
Table 2. Productive structure of the system based on the E Model.

\begin{tabular}{|c|c|c|c|c|}
\hline \multirow{2}{*}{ Subsystem } & \multicolumn{2}{|c|}{ Fuel } & \multicolumn{2}{|c|}{ Product } \\
\hline & Physical & Productive & Physical & Productive \\
\hline CIC & $\mathrm{P}_{\mathrm{LC}}+\mathrm{P}_{\mathrm{HC}}$ & $\mathrm{P}_{\mathrm{LC}}+\mathrm{P}_{\mathrm{HC}}$ & $\left(\mathrm{E}_{2}-\mathrm{E}_{1}\right)$ & $E_{2: 1}$ \\
\hline $\mathrm{R}$ & $\left(\mathrm{E}_{7}-\mathrm{E}_{8}\right)$ & $\mathrm{E}_{7: 8}$ & $\left(\mathrm{E}_{5}-\mathrm{E}_{4}\right)$ & $E_{5: 4}$ \\
\hline $\mathrm{CC}$ & $\mathrm{Q}_{\mathrm{F} 1}$ & $\mathrm{Q}_{\mathrm{F} 1}$ & $\left(\mathrm{E}_{6}-\mathrm{E}_{5}\right)$ & $\mathrm{E}_{6: 5}$ \\
\hline GT & $\left(\mathrm{E}_{6}-\mathrm{E}_{7}\right)$ & $\mathrm{E}_{6: 7}$ & $\mathrm{P}_{\mathrm{LC}}+\mathrm{P}_{\mathrm{HC}}+\mathrm{P}_{\mathrm{N}}$ & $\mathrm{P}_{\mathrm{LC}}+\mathrm{P}_{\mathrm{HC}}+\mathrm{P}_{\mathrm{N}}$ \\
\hline SF & $\mathrm{Q}_{\mathrm{F} 2}$ & $\mathrm{Q}_{\mathrm{F} 2}$ & $\left(\mathrm{E}_{9}-\mathrm{E}_{8}\right)$ & $\mathrm{E}_{9: 8}$ \\
\hline $\mathrm{RB}$ & $\left(\mathrm{E}_{9}-\mathrm{E}_{10}\right)$ & E9:10 & $\mathrm{Qu}$ & $\mathrm{Qu}$ \\
\hline
\end{tabular}

Table 3. Productive structure of the system based on the H\&S Model.

\begin{tabular}{|c|c|c|c|c|}
\hline \multirow{2}{*}{ Subsystem } & \multicolumn{2}{|l|}{ Fuel } & \multicolumn{2}{|c|}{ Product } \\
\hline & Physical & Productive & Physical & Productive \\
\hline $\mathrm{LC}$ & $\mathrm{P}_{\mathrm{LC}}+\left(\mathrm{S}_{2}-\mathrm{S}_{1}\right)$ & $\mathrm{P}_{\mathrm{LC}}+\mathrm{S}_{2: 1}$ & $\left(\mathrm{H}_{2}-\mathrm{H}_{1}\right)$ & $\mathrm{H}_{2: 1}$ \\
\hline IC & $\left(\mathrm{H}_{2}-\mathrm{H}_{3}\right)$ & $\mathrm{H}_{2: 3}$ & $\left(\mathrm{~S}_{2}-\mathrm{S}_{3}\right)$ & $\mathrm{S}_{2: 3}$ \\
\hline $\mathrm{HC}$ & $\mathrm{P}_{\mathrm{HC}}+\left(\mathrm{S}_{4}-\mathrm{S}_{3}\right)$ & $\mathrm{P}_{\mathrm{HC}}+\mathrm{S}_{4: 3}$ & $\left(\mathrm{H}_{4}-\mathrm{H}_{3}\right)$ & $\mathrm{H}_{4: 3}$ \\
\hline $\mathrm{R}$ & $\left(\mathrm{H}_{7}-\mathrm{H}_{8}\right)+\left(\mathrm{S}_{5}-\mathrm{S}_{4}\right)$ & $\mathrm{H}_{7: 8}+\mathrm{S}_{5: 4}$ & $\left(\mathrm{H}_{5}-\mathrm{H}_{4}\right)+\left(\mathrm{S}_{7}-\mathrm{S}_{8}\right)$ & $\mathrm{H}_{5: 4}+\mathrm{S}_{7: 8}$ \\
\hline $\mathrm{CC}$ & $\mathrm{Q}_{\mathrm{F} 1}+\left(\mathrm{S}_{6}-\mathrm{S}_{5}\right)$ & $\mathrm{Q}_{\mathrm{F} 1}+\mathrm{S}_{6: 5}$ & $\left(\mathrm{H}_{6}-\mathrm{H}_{5}\right)+\left(\mathrm{E}^{\mathrm{CH}_{6}}-\mathrm{E}^{\mathrm{CH}_{5}}\right)$ & $\mathrm{H}_{6: 5}+\mathrm{E}^{\mathrm{CH}_{6: 5}}$ \\
\hline GT & $\left(\mathrm{H}_{6}-\mathrm{H}_{7}\right)+\left(\mathrm{S}_{7}-\mathrm{S}_{6}\right)$ & $\mathrm{H}_{6: 7}+\mathrm{S}_{7: 6}$ & $\mathrm{P}_{\mathrm{LC}}+\mathrm{P}_{\mathrm{HC}}+\mathrm{P}_{\mathrm{N}}$ & $\mathrm{P}_{\mathrm{LC}}+\mathrm{P}_{\mathrm{HC}}+\mathrm{P}_{\mathrm{N}}$ \\
\hline SF & $\mathrm{Q}_{\mathrm{F} 2}+\left(\mathrm{S}_{9}-\mathrm{S}_{8}\right)$ & $\mathrm{Q}_{\mathrm{F} 2}+\mathrm{S}_{9: 8}$ & $\left(\mathrm{H}_{9}-\mathrm{H}_{8}\right)+\left(\mathrm{E}^{\mathrm{CH}_{9}}-\mathrm{E}^{\mathrm{CH}_{8}}\right)$ & $\mathrm{H}_{9: 8}+\mathrm{E}^{\mathrm{CH}_{9: 8}}$ \\
\hline $\mathrm{RB}$ & $\left(\mathrm{H}_{9}-\mathrm{H}_{10}\right)$ & $\mathrm{H}_{9: 10}$ & $\mathrm{Qu}_{\mathrm{U}}+\left(\mathrm{S}_{9}-\mathrm{S}_{10}\right)$ & $\mathrm{Qu}_{\mathrm{U}}+\mathrm{S}_{9: 10}$ \\
\hline ENV & $\left(\mathrm{H}_{10}-\mathrm{H}_{1}\right)+\left(\mathrm{E}^{\mathrm{CH}_{6}}-\mathrm{E}^{\mathrm{CH}_{5}}\right)+\left(\mathrm{E}^{\mathrm{CH}_{9}}-\mathrm{E}^{\mathrm{CH}_{8}}\right)$ & $\mathrm{H}_{10: 1}+\mathrm{E}^{\mathrm{CH}_{6: 5}}+\mathrm{E}^{\mathrm{CH}_{9: 8}}$ & $\left(\mathrm{~S}_{10}-\mathrm{S}_{1}\right)$ & $\mathrm{S}_{10: 1}$ \\
\hline
\end{tabular}

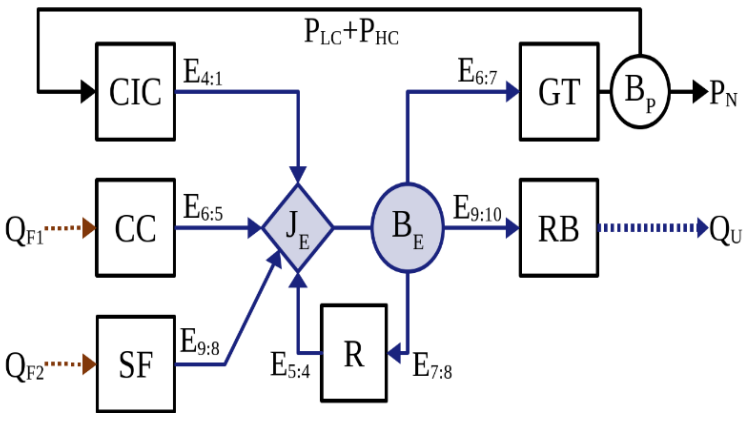

Fig. 2 Productive diagram for the cogeneration system using E Model, Arrangement 1.

Based on the above, the productive diagram of the system in Fig. 1 was elaborated for E Model, being presented in Figs. 2 and 3 . The diagram uses the total exergy flows to define the fuel and product of the productive subsystems. In this case, the intercooler is a dissipative equipment, in which the E Model is unable to clearly define its product, i.e., the specific variation of the total exergy between states 2 and 3, presents a negative value. Thus, for this equipment, the exergy $\left(E_{2: 3}\right)$ is considered fuel, and it would not be possible to quantify or define the intercooler product (or function) in terms of total exergy. ${ }^{[14]}$ Therefore, it cannot be isolated in the productive diagram. As an alternative, the intercooler could be aggregated to any other component, then the authors decide arbitrarily to merge it into the low and high-pressure air compressors, forming a subsystem called CIC, in order to define its productive purpose. Local optimization and diagnosis of malfunctions require the isolation of all equipment, which would not be achieved in this case.

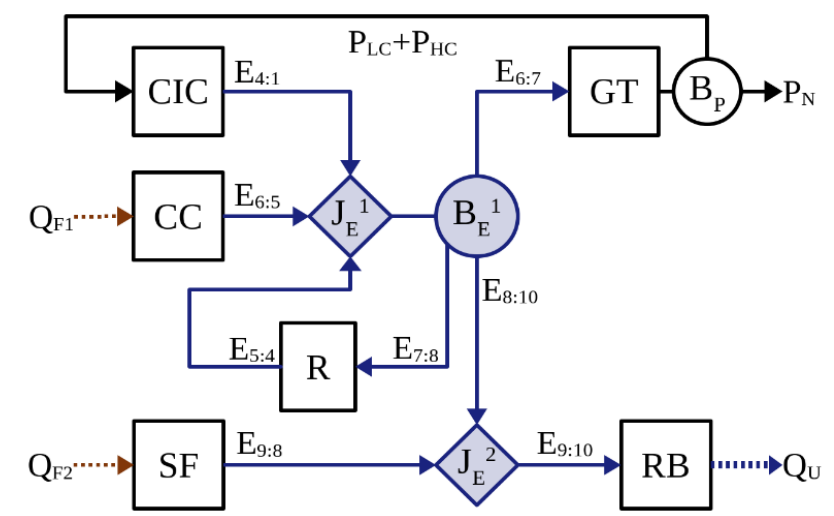

Fig. 3 Productive diagram for the cogeneration system using E Model, Arrangement 2.

Figure 4 represents the productive diagram of the cogeneration system using the $\mathrm{E}$ Model in all productive units, except in the intercooler, where the H \& S Model is applied. When compared to the productive diagram using only $\mathrm{H} \& \mathrm{~S}$ Model, this method reduced the complexity and isolated the intercooler. Furthermore, it is worth mentioning that the exergetic balance at the junction and bifurcation remains consistent. 


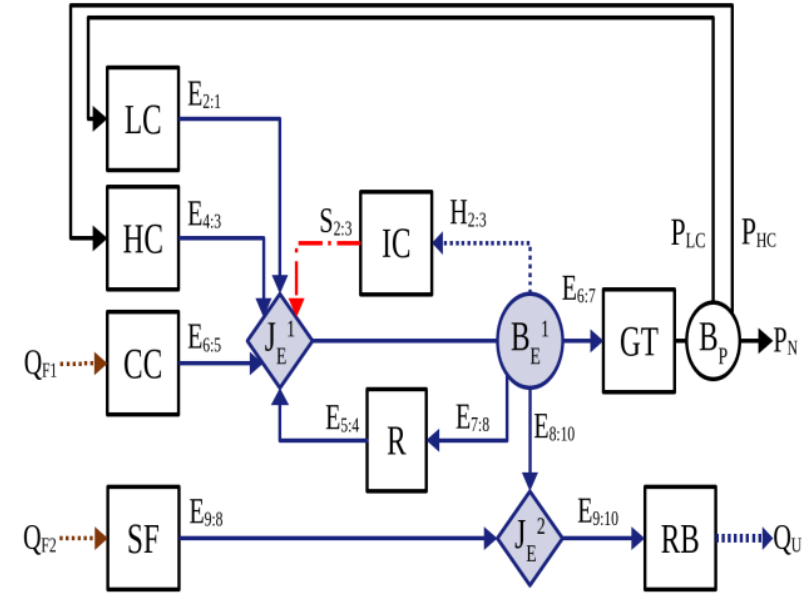

Fig. 4 Productive diagram for the cogeneration system using localized physical exergy disaggregation.

In arrangement 1, shown in Fig. 2, the supplementary firing allocates the extra exergy to the power and the useful heat. Furthermore, there is no differentiation in the treatment between the combustions, i.e., it presents only a pair of fictitious units $\left(\mathrm{J}_{\mathrm{E}}\right.$ and $\left.\mathrm{B}_{\mathrm{E}}\right)$ that receive all the product from the subsystems that increase the working fluid exergy (CIC, CC, $\mathrm{R}$, and $\mathrm{SF}$ ) and distribute it as fuel for the subsystems that reduce the working fluid exergy.

In arrangement 2, shown in Fig. 3, the dissipative component analysis receives the same treatment as in the previous case. One may notice a new junction $\left(\mathrm{J}_{\mathrm{E}}^{2}\right)$, which receives extra exergy from the supplementary firing and the exergy $\left(\mathrm{E}_{8: 10}\right)$ from the bifurcation $\left(\mathrm{B}_{\mathrm{E}}{ }^{1}\right)$. This structure ensures that the supplementary firing allocates the extra exergy only to the useful heat through the junction $\left(\mathrm{J}_{\mathrm{E}}{ }^{2}\right)$, while the combustion chamber distributes the exergy proportionally to the power and useful heat.

In Fig. 4, arrangement 2 is chosen as a base because supplementary firing costs are allocated only to the subsystem that uses the extra exergy, so this case is more coherent. The difference is the localized physical exergy disaggregation applied at the dissipative component through the H\&S Model to isolate it. In addition, the cost formation process becomes more accurate with the subsystem CIC disaggregation. Thereby, the intercooler fuel is the enthalpy productive flow $\left(\mathrm{H}_{2: 3}\right)$ coming from the bifurcation $\left(\mathrm{B}_{\mathrm{E}}{ }^{1}\right)$ and the product is the entropy productive flow $\left(\mathrm{S}_{2: 3}\right)$ returning to the junction $\left(\mathrm{J}_{\mathrm{E}}{ }^{1}\right)$. In all Figs. 2 to 4 , the waste cost is implicitly and proportionally allocated to the exergy consumption in the production unit that produces the final products.

\subsubsection{H \& S Model}

By disaggregating physical exergy, it is possible to obtain a better accuracy of the results in the thermoeconomic analysis. Nonetheless, there is an increase in complexity. ${ }^{[7,12]}$ In this way, to decompose the CIC subsystem and thus obtain the product and fuel of the intercooler (dissipative equipment), it at least is necessary to disaggregate the physical exergy into its enthalpic and entropic terms. The H \& S Model ${ }^{[10,11]}$ was the first thermoeconomic methodology capable of defining fuel and product, in addition to isolating the dissipative equipment (condenser) in the productive diagram, without inconsistencies.

According to Valero et al., ${ }^{[50]}$ the costs, efficiencies, and behavior of the system are based on the resource consumption, which in turn is based on the trajectories of the flows in the hs plane when it works for the specific purpose of the plant. This is exactly what the H\&S Model does, it describes the behavior of thermodynamic cycles in the h-s plane taking into account the variation of enthalpy and entropy of the working fluid.

As reported by Torres et al., ${ }^{[28]}$ the conventional thermoeconomic methodologies do not consider the in-depth analysis of the cost allocation, thus one needs to develop new techniques or enhance the existing ones to include both the residues cost allocation and the analysis of their formation process. Differently, the H \& S Model was elaborated thinking in the residue cost allocation and in the dissipative equipment isolation. Through the definition, its productive structure is based on enthalpic, entropic, and chemical exergy terms.

For that purpose, the $\mathrm{H} \& \mathrm{~S}$ Model takes advantage of the elegance of the negentropic flow idea, ${ }^{[13,42]}$ adopting it as an entropic term of exergy, which is used together with the enthalpic term, according to the exergy definition, Eq. (5). Also, according to the $\mathrm{H} \& \mathrm{~S}$ Model, chemical exergy $\left(\mathrm{E}^{\mathrm{CH}_{\mathrm{i} j}}\right)$ is shown in the productive diagram, explicitly.

In the $\mathrm{H} \& \mathrm{~S}$ model, there is a device called environment (ENV), which has the function of dissipating the existing waste (flow 10), thus making the cost allocation of waste explicit. From the environment, the entropic term is distributed to those units that increase the working fluid entropy. The chemical exergy caused by the combustion process in the combustion chamber $\left(\mathrm{E}^{\mathrm{CH}}{ }_{6: 5}\right)$ and the supplementary firing $\left(\mathrm{E}^{\mathrm{CH}_{9: 8}}\right)$ is also dissipated in the environment.

Figure 5 and 6 represent the productive diagrams applied to the $\mathrm{H} \& \mathrm{~S}$ Model in the studied system. It is also possible to verify that all units are isolated in the diagrams.

Figure 5 represents the productive diagram of the cogeneration system considering the $\mathrm{H} \& \mathrm{~S}$ Model Arrangement 1. All the subsystems define a product and fuel, besides isolating the intercooler without inconsistencies. In this arrangement, there is only one pair of fictitious units for enthalpy $\left(\mathrm{J}_{\mathrm{H}}\right.$ and $\left.\mathrm{B}_{\mathrm{H}}\right)$, that receive the $\mathrm{CC}$ product $\left(\mathrm{H}_{6: 5}\right)$ and SF product $\left(\mathrm{H}_{9: 8}\right)$. Consequently, the junction and the bifurcation $\left(\mathrm{J}_{\mathrm{H}}\right.$ and $\left.\mathrm{B}_{\mathrm{H}}\right)$ receive all the flows that increase the enthalpic term and distribute to those that decrease it.

Fig. 6 represents the productive diagram of the cogeneration system using the $\mathrm{H} \& \mathrm{~S}$ Model - Arrangement 2 . There are a new junction and a new bifurcation for the enthalpic term $\left(\mathrm{J}_{\mathrm{H}}^{2}-\mathrm{B}_{\mathrm{H}}^{2}\right)$, allowing the allocation of the supplement firing product $\left(\mathrm{H}_{9: 8}\right)$ only to those which use it, i.e., the useful heat. 


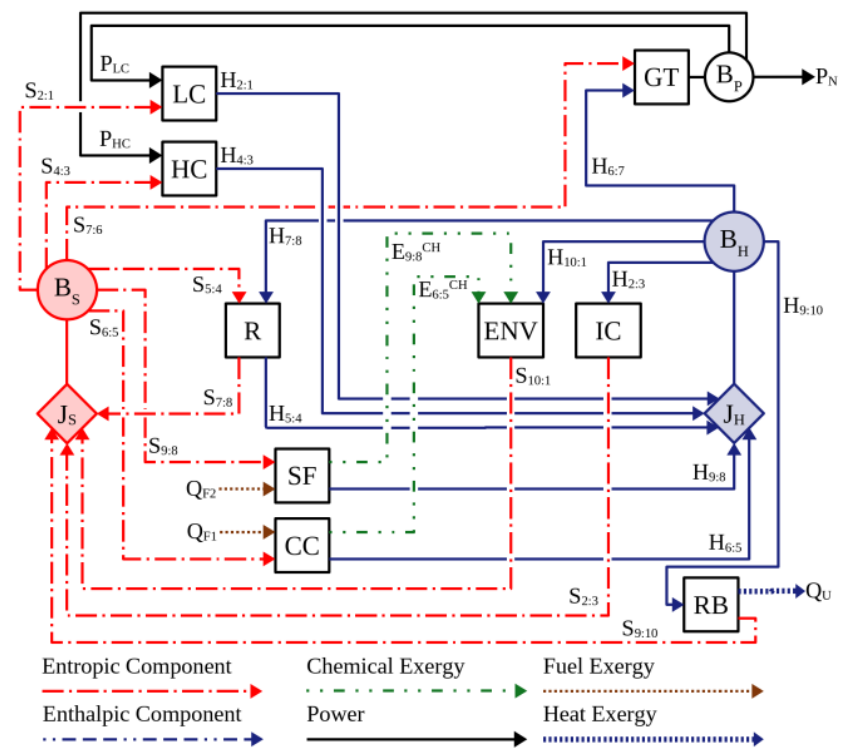

Fig. 5 Productive diagram for the cogeneration system using H\&S Model - Arrangement 1.

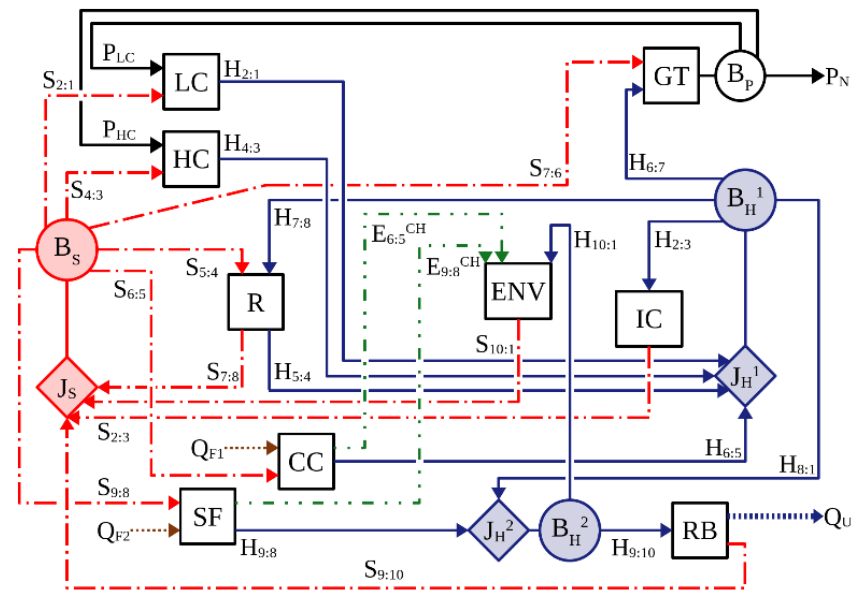

Fig. 6 Productive diagram for the cogeneration system using H\&S Model - Arrangement 2.

\subsection{Comprehensive diagram}

The comprehensive diagram is an alternative to the arbitrariness present in the productive diagram since physical flows are used for the interconnections between the subsystems, and besides giving physical meaning to the flows. The main characteristic of the comprehensive diagram is the use of physical flows for the interconnections between subsystems, in addition to evaluating the internal unit costs of physical and productive flows in the same diagram. ${ }^{[12,21,25,26]}$

The comprehensive diagram methodology was developed based on works. ${ }^{[12,13,21]}$ Frangopoulos et al. ${ }^{[13]}$ developed an intermediate thermoeconomic diagram using productive flows and physical flow loops. The concept of internal loop flows was discussed. ${ }^{[33]}$ This diagram did not use the junctions and bifurcations present in the productive diagram. Nevertheless, the author did not proceed with the development. The direct calculation of costs from the productive structure was realized by Lazzaretto et al. ${ }^{[21]}$ Lazzaretto and Tsatsaronis $^{[12]}$ discussed the concepts of productive unit and component to elaborate the diagram and equation system. According to the authors, the productive unit explicitly shows the fuel and product interactions between the component itself and the exergy streams by acting as a collector and distributor of fuel and product terms. Since the fictitious branches and junctions remain within the boundaries of the component, the interconnections among components remain in the productive structure as in the flow diagram that represents the physical structure of the system. There is a similar diagram to the comprehensive diagram used to cost allocation presented. ${ }^{[3,27]}$

In the comprehensive diagrams of Figs. 7 to 10 , it is not possible to develop different arbitrary arrangements to interconnect the subsystems due to the use of physical flows. The subsystem representation is established as: the dotted lines are the components, and the continuous lines are the productive units. The product and fuel definitions are the same as explained in the productive diagram for each model.

\subsubsection{E Model}

Figures 7 and 8 represent the comprehensive diagram of the cogeneration system with a regenerative gas turbine, intercooler, and supplementary firing applied to the E Model with different ways of structural waste cost allocation.

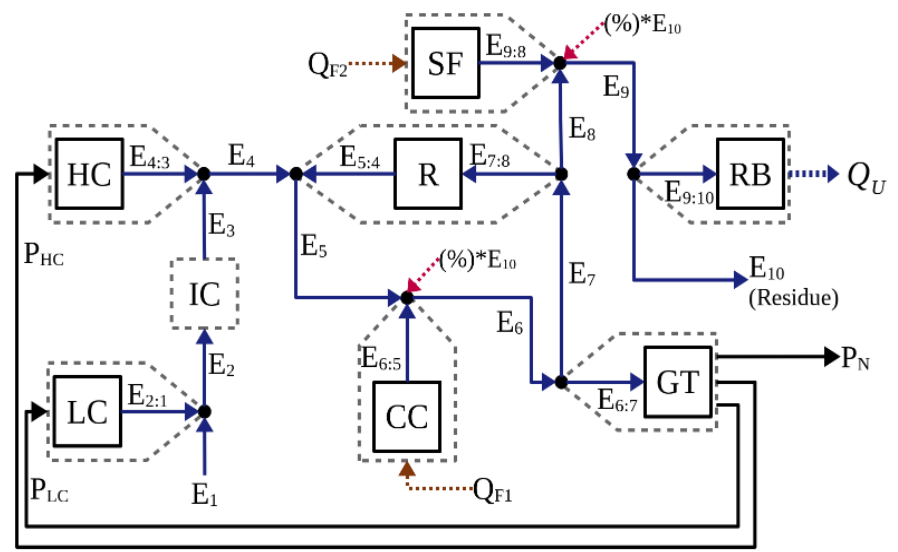

Fig. 7 Comprehensive diagram for the system using E Model Residue cost allocation in the SPECO-based approach.

In an open system as in this case, the comprehensive diagram using E Model, the ambient air enters into a lowpressure air compressor, and the exhaust gas (flow 10) is released into the environment. This occurs because the internal loop of the physical exergy flow is opened, shown in Figs. 7 to 9 . Therefore, the cost of this waste needs to be reinternalized to the system to be distributed to the final products.

In the last years, many works $^{[8,12,28,30,31,38,39,51]}$ proposed several criteria to distribute the waste cost, being common in the use of residue cost distribution ratio, which represents the fraction of the total cost of a waste that is allocated to a given component. All those criteria are arbitrary, as there are different ways to define the value of this ratio for reallocating the waste to the components in which it was generated. 


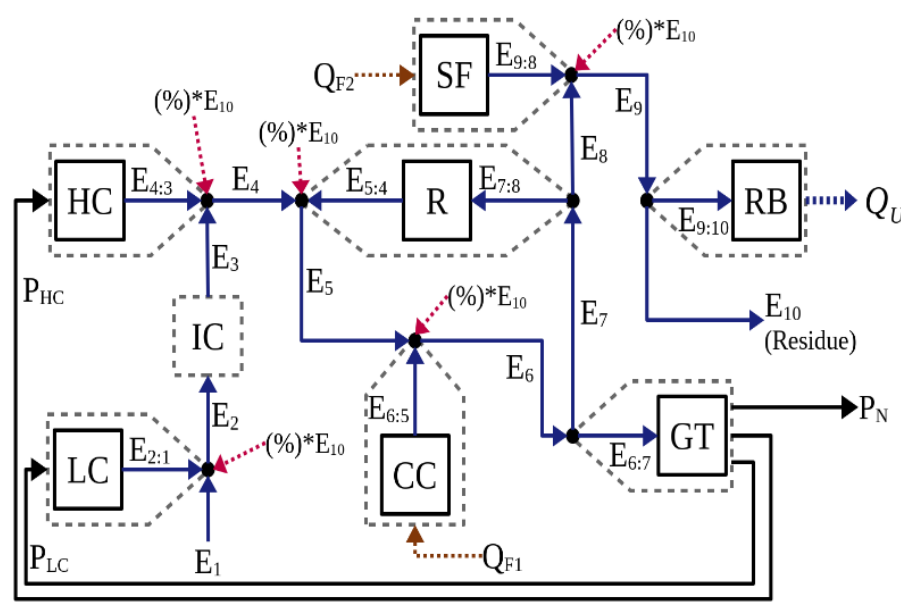

Fig. 8 Comprehensive diagram for the system using E Model Residue cost allocation in the Internal loop of physical flows.

It is relevant to note that for the intercooler (IC), the dissipative equipment, the $\mathrm{E}$ Model does not define its function. The intercooler is only treated through the physical flows of the plant when utilizing the $\mathrm{E}$ Model in the comprehensive diagram. It is important to emphasize that treating a subsystem in the diagram is not the same as isolating it. According to R. B. Evans, ${ }^{[52]}$ isolation defines the fuel and product of the subsystems. This is not the case, where the intercooler input and output flows cannot be treated as fuel and product, and this equipment acts only as a component.

Despite the comprehensive diagram treating the dissipative equipment through physical flows and reducing the interconnections arbitrariness due to the removal of the junction-bifurcation, there is arbitrariness in the residues treatment criteria when E Model is applied. In this work, two waste cost allocation ratios are adopted, which are present in Figs. 7 and 8. In Fig. 7, the waste cost allocation is adopted, ${ }^{[12]}$ which reinternalizes the waste costs to the component that generated it. In this case, it is arbitrarily distributed proportionally to its exergy input, that is, $94.13 \%$ for $\mathrm{CC}$ and $5.87 \%$ for SF.

In Fig. 8, the waste cost allocation ratio is adopted, ${ }^{[28]}$ whose waste cost is arbitrarily allocated proportionally to the increase in the exergy of the working fluid in the component. In the comprehensive diagram, the waste cost is allocated directly in the loop of the physical flow, ${ }^{[38,39]}$ indicated by the red arrows. In this case, the residue cost distribution ratios used are $9.19 \%$ for LC, $9.54 \%$ for HC, $28.64 \%$ for R, $49.67 \%$ for $\mathrm{CC}$, and $2.96 \%$ for $\mathrm{SF}$.

In Fig. 9, the same waste cost allocation is applied as in Fig. 8 (internal loop of physical flow). The difference is that the localized physical exergy disaggregation is applied at the dissipative component through the H\&S Model to isolate it. Thereby, the input and output flow to the IC component based on $\mathrm{E}$ Model is $\mathrm{E}_{2}$ and $\mathrm{E}_{3}$, respectively, and the intercooler fuel is the enthalpy productive flow $\left(\mathrm{H}_{2: 3}\right)$ and the product is the entropy productive flow $\left(\mathrm{S}_{2: 3}\right)$.

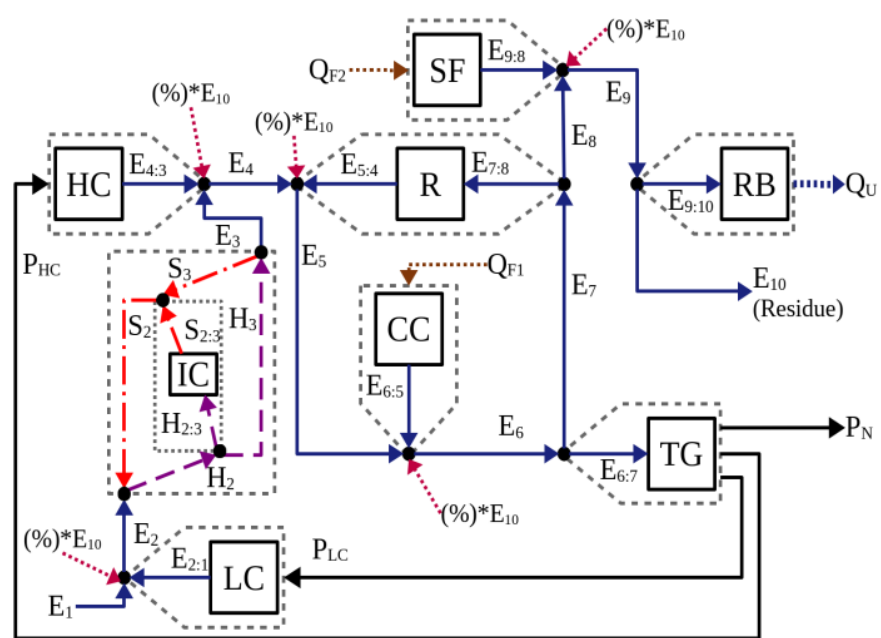

Fig. 9 Comprehensive diagram for the system using Localized Exergy Disaggregation.

\subsubsection{H \& S Model}

The system for the H\&S Model in the comprehensive diagram is shown in Fig. 10. As in the productive diagram, the intercooler (dissipative equipment) is isolated defining the product and fuel through the enthalpic and entropic terms. The waste treatment is an inherent feature of the H\&S Model that was allocated automatically and systematically through the definition of its productive structure. Unlike the productive diagram, chemical exergy presents a loop of physical flow in the system, however, only some equipment has fuel and product. Hence, productive flows are defined only at $\mathrm{CC}, \mathrm{SF}$, and $\mathrm{ENV}$, in the other equipment, there is no variation in the chemical exergy.

Looking only at the chemical exergy flows, the flows $\mathrm{E}^{\mathrm{CH}_{1}}$ to $\mathrm{E}^{\mathrm{CH}_{5}}$ present a null value, since there is no change in the chemical composition of air. The value is the same inflows $\mathrm{E}^{\mathrm{CH}_{6}}$ to $\mathrm{E}^{\mathrm{CH}_{8}}$, due to the combustion process after the combustion chamber, in which there is a modification in the composition in relation to air, causing the chemical exergy to change. The chemical exergy values of the $\mathrm{E}^{\mathrm{CH}_{9}}$ and $\mathrm{E}^{\mathrm{CH}}{ }_{10}$ flows are equal, as a result of the new combustion process in the supplementary firing.

\section{Results and discussions}

For the cogeneration system with a regenerative gas turbine, intercooler, and supplementary firing, two thermoeconomic models, $\mathrm{E}$ and $\mathrm{H} \& \mathrm{~S}$ were applied using productive and comprehensive diagrams. Due to the arbitrariness of the productive diagram construction, it was possible to arbitrarily elaborate two diagrams with different cost allocations due to the additional heat of the supplementary firing. Regarding the comprehensive diagram, for $\mathrm{E}$ Model, two criteria of allocating the waste cost were arbitrarily used. 


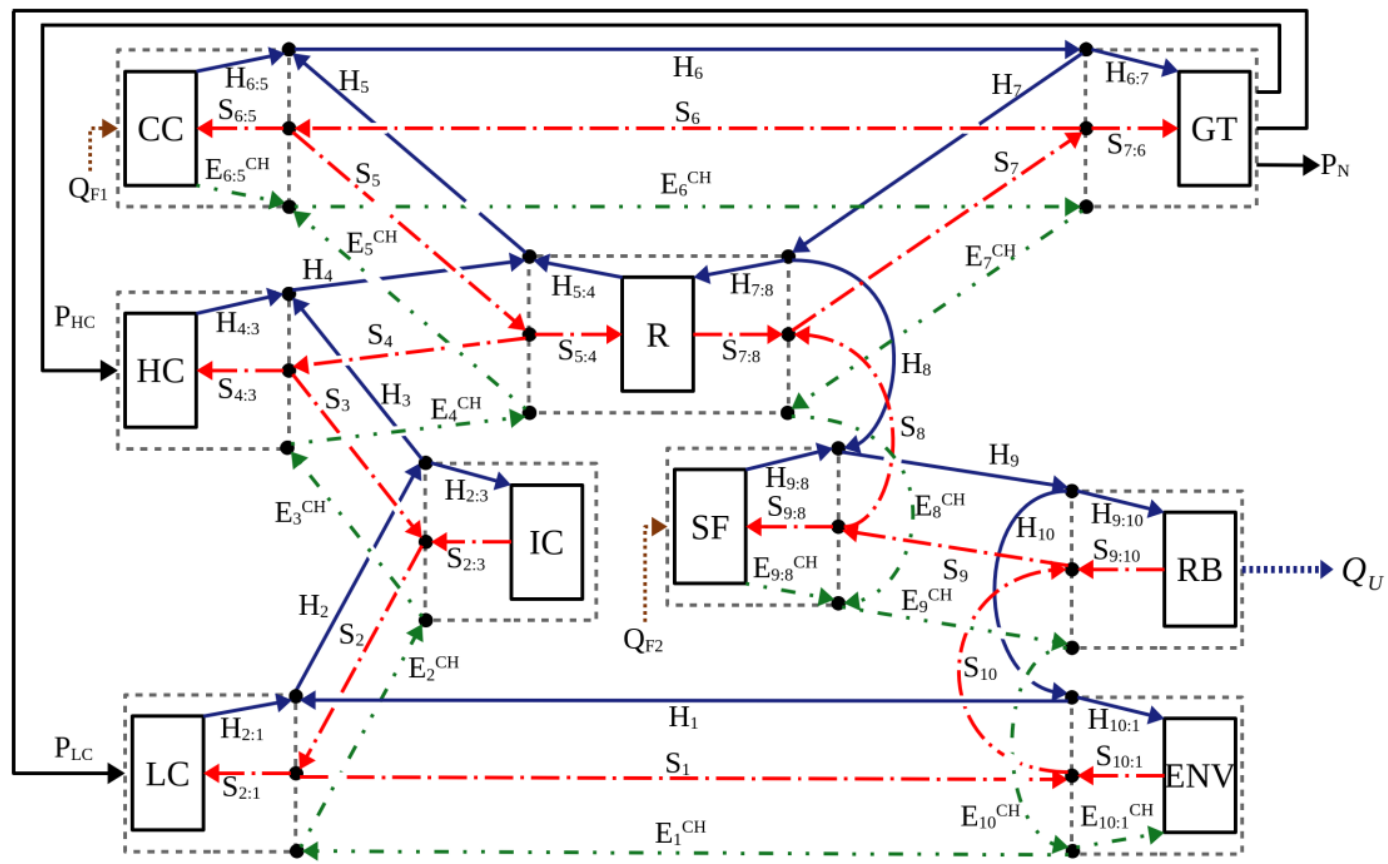

Fig. 10 Comprehensive diagram of the system using the H\&S Model.

Regarding the dissipative equipment (intercooler), the productive diagram using E Model needs to merge arbitrarily the intercooler with the air compressors, creating the CIC subsystem. This new system could determine the fuel and product. On the other hand, in the comprehensive diagrams, the intercooler was treated by physical flows, that allowed the separating of the air compressors. An alternative to isolating the dissipative equipment was localized physical exergy disaggregation. This methodology applied to the productive and comprehensive diagrams at E Model allowed us to define the fuel and product of the intercooler without increasing the complexity when compared to applying the H\&S Model in the whole system.

According to de Araújo et al., ${ }^{[41]}$ regardless of the cost allocation procedure, the result of the products unit cost will always form a straight line with the solution defined by
Eq. (7) to this work. This equation shows that there is a correlation between the exergetic unit cost of power and the exergetic unit cost of heat.

$$
k_{P}=-\frac{Q_{U}}{P_{N}} \cdot k_{Q_{U}}+\frac{\left(Q_{F 1}+Q_{F 2}\right)}{P_{N}} \cdot k_{F}
$$

Figure 11 shows the straight line with the results obtained by different cost allocation methods for the same system. All points in Fig. 11 are ordered pairs of heat and power unit costs obtained by the methodologies studied in this work, which are in the straight line with the solution, thus providing coherent results, i.e., the exergetic unit costs of internal flows and products are superior to one. It is important to highlight the choice of the diagram and the exergy disaggregation model for determining the cost formation process of the products. Table 5 summarizes the results of exergetic unit costs of products from different approaches to cost allocation.

Table 4. Exergetic unit cost of power and heat - E and H\&S Model.

\begin{tabular}{|c|c|c|c|c|c|c|}
\hline \multirow{2}{*}{ Model } & \multirow{2}{*}{ Diagram } & \multirow{2}{*}{ Arrangement } & \multirow{2}{*}{ Figure } & \multicolumn{2}{|c|}{ Exergetic Unit Cost $(\mathrm{kJ} / \mathrm{kJ})$} & \multirow{2}{*}{$\begin{array}{c}\text { Quantity of } \\
\text { flows }\end{array}$} \\
\hline & & & & Heat & Power & \\
\hline $\mathrm{E}$ & Productive & Arrangement 1 - one pair of J-B & 2 & 1.647 & 1.405 & 11 \\
\hline $\mathrm{E}$ & Productive & Arrangement 2 - two pairs of J-B & 3 & 1.536 & 1.424 & 12 \\
\hline $\mathrm{E}$ & Productive & Localized Exergy Disaggregation & 4 & 1.536 & 1.424 & 15 \\
\hline $\mathrm{H} \& \mathrm{~S}$ & Productive & Arrangement 1 - one pair of J-B & 5 & 1.494 & 1.431 & 26 \\
\hline $\mathrm{H} \& \mathrm{~S}$ & Productive & Arrangement 2 - two pair of J-B & 6 & 1.491 & 1.431 & 27 \\
\hline $\mathrm{E}$ & Comprehensive & SPECO based approach & 7 & 1.591 & 1.414 & 22 \\
\hline $\mathrm{E}$ & Comprehensive & Internal Loop & 8 & 1.579 & 1.416 & 22 \\
\hline $\mathrm{E}$ & Comprehensive & Localized Exergy Disaggregation & 9 & 1.579 & 1.416 & 28 \\
\hline $\mathrm{H} \& \mathrm{~S}$ & Comprehensive & & 10 & 1.501 & 1.429 & 57 \\
\hline
\end{tabular}




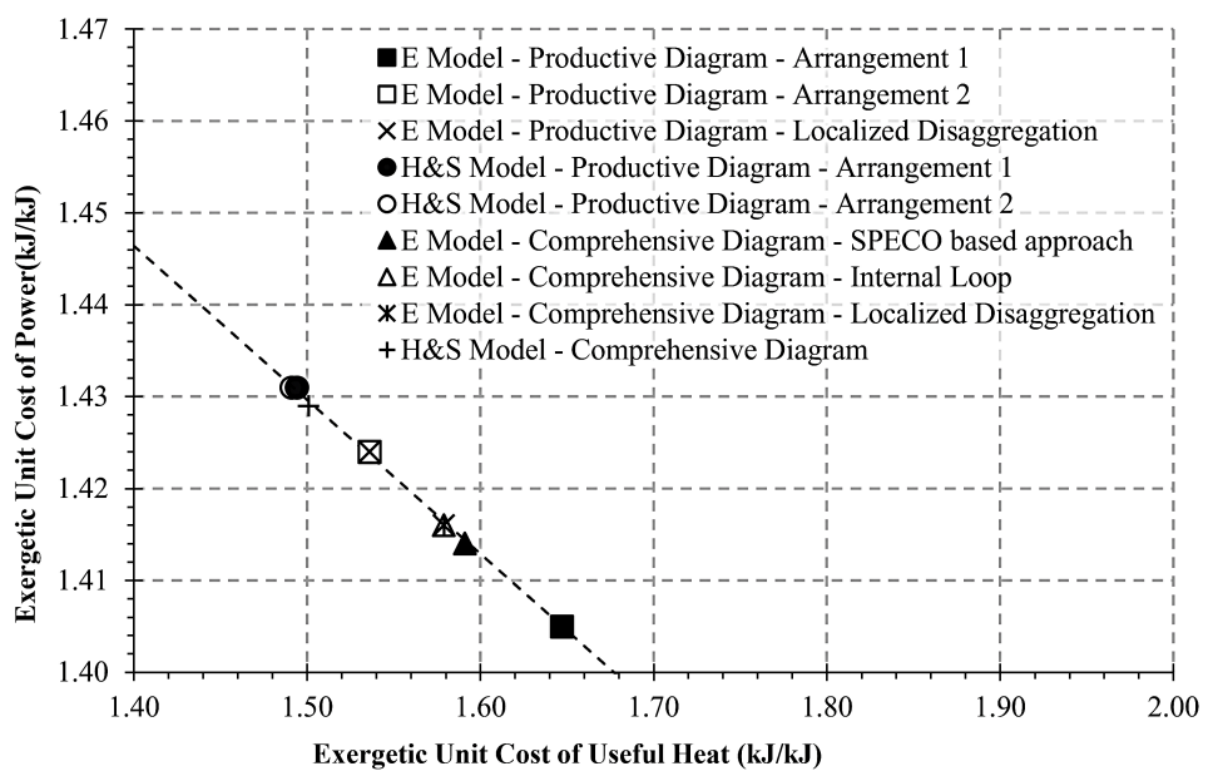

Fig. 11 Results obtained by the different cost allocation methods for the same system at the straight line with the solution.

Arrangement 1 of the E Model productive diagram gave the highest exergetic unit cost of heat $(1.647 \mathrm{~kJ} / \mathrm{kJ})$ and consequently the lowest value for power $(1.405 \mathrm{~kJ} / \mathrm{kJ})$. On the other side, arrangement 2 of the H\&S Model productive diagram gave the lowest value for the unit exergetic cost of heat $(1.491 \mathrm{~kJ} / \mathrm{kJ})$ and the highest value for power $(1.431$ $\mathrm{kJ} / \mathrm{kJ})$.

Figure 11 also highlights a distinct behavior between the $\mathrm{E}$ and $\mathrm{H} \& \mathrm{~S}$ thermoeconomic models. The E Model overloads the exergetic unit cost of heat, while the $\mathrm{H} \& \mathrm{~S}$ Model overloads the exergetic unit cost of the power. This is explained by the dissipative equipment isolation in the H\&S Model, as well as by different waste allocation procedures for each thermoeconomic model. In the $\mathrm{E}$ Model with a productive diagram, the waste cost allocation is carried out implicitly and proportionally to the power and heat, i.e., the waste cost is allocated proportionally to the inputs of the gas turbine and the recovery boiler. In the $\mathrm{H} \& \mathrm{~S}$ Model, it is allocated to subsystems that increase working fluid entropy. Thus, among the equipment that reduces entropy is the recovery boiler, consequently not receiving any waste cost allocation, which results in a decrease in the heat unit cost.

Regarding the localized physical exergy disaggregation, in the E Model, the exergetic unit costs of the product and internal flow were the same in the productive diagram in arrangement 2 and localized exergy disaggregation, and also in the comprehensive diagram with internal loop and localized exergy disaggregation (see Table S2 and S3). As for the productive flows $\mathrm{H}_{2: 3}$ and $\mathrm{S}_{2: 3}$, they were different when compared to the H\&S Model applied in the comprehensive diagram and with a small difference in the production diagram. Still concerning the E Model, the localized physical disaggregation allowed us to define the fuel and product of the intercooler (dissipative equipment) besides reducing approximately $50 \%$ the quantity of flow, when compared to the H \& S Model, i.e., it was possible to define the function of the dissipative equipment without increasing its complexity, through the localized physical disaggregation.

Analyzing only the productive diagrams, the influence of fictitious components on the cost allocation is observed. When the productive diagram presents only one pair of junctions and bifurcation (arrangement 1), regardless of the thermoeconomic model, the heat is always penalized, since the bifurcation unit cost possesses a higher value in relation to the product unit cost of supplementary firing. The authors consider a more coherent case with two pairs of junctions and bifurcations (arrangement 2). After all, the costs of supplementary firing are allocated only to the equipment that used the added extra energy, in this case, the recovery boiler. The recovery boiler cost is comprised of the supplementary firing product cost and the productive flow cost coming from the bifurcation $\left(\mathrm{B}_{\mathrm{E}}^{1}\right.$ or $\left.\mathrm{B}_{\mathrm{H}}^{1}\right)$. As the supplementary firing unit cost is lower than that of the productive flow, it results in a reduction in the unit cost of heat and, consequently, an increase in the unit cost of power.

Comparing different arrangements of the productive diagram applied in the E Model, the exergetic unit costs of the products obtained by this model showed the greatest variation, $1.33 \%$ and $7.29 \%$ for power and heat, respectively. These values are obtained in relation to the lowest value of exergetic unit costs from the arrangements of the productive diagram applied in the E Model. The same comparison was made for the H \& S Model, which presented values of $0.12 \%$ and $0.67 \%$. When comparing different diagrams, the $\mathrm{H} \& \mathrm{~S}$ Model in the comprehensive diagram showed a reduction in the exergetic unit cost of power $(0.119 \%)$ and an increase in the unit cost of heat $(0.67 \%)$, in relation to that obtained by arrangement 2 of the productive diagram. This difference is mainly due to the subsystem's interconnection rather than the waste cost allocation. Unlike the H \& S Model, the E Model showed a 
significant variation in the cost allocation procedures between the diagrams. This difference is because the cost formation process between the diagrams is different, i.e., the comprehensive diagram respects the subsystem interconnections presented in the physical diagram, while the productive diagram uses productive flows, which may not have a physical meaning, in addition to the junctions and bifurcations arbitrariness. ${ }^{[4]}$

The $\mathrm{H} \& \mathrm{~S}$ Model is a methodology designed to perform waste treatment without the use of other methodologies since the waste treatment is established in the model itself through the productive structure. In addition, it is independent of the chosen diagram. This behavior is evident by the variation of the results obtained by the model, which is quite low. For the E Model in the comprehensive diagram, there is a need to use separate methodologies to perform the waste treatment. The internal loop methodology ends up overloading the power since the waste cost is distributed to that equipment which increases exergy. On the other hand, under SPECO based approach, the heat is overloaded, and the waste is allocated only to those who generate it, in this case, the combustion chamber and the supplementary firing. However, these results showed less variation than those of the productive diagram.

The difference between arrangement 1 (one pair of junctions and bifurcation) and arrangement 2 (two pairs of junctions and bifurcation) reveals a slight difference in the exergetic unit cost for internal flows. Although, arrangement 2 allocates extra exergy from supplementary firing more rationally, as already explained. Tables S2 and S3, in the supplementary information, show the exergetic unit cost for internal flows of the $\mathrm{E}$ and $\mathrm{H} \& \mathrm{~S}$ Models in productive and comprehensive diagrams.

One may summarize the main results drawn from each modeling of allocation as follow:

- The exergetic unit cost of power is more penalized when it is calculated by arrangement 1 (one pair of $\mathrm{J}$ B) than arrangement 2 (two pairs of J-B) due to different allocation of the extra external fuel exergy added in the SF. Arrangement 2 is more rational. After all, the extra external fuel exergy from the SF is allocated only to the recovery boiler, not penalizing the power cost.

- The Productive diagram could contain arbitrariness related to the subsystem interconnected by the use of fictitious units (junction and bifurcation) as seen through arrangements 1 and 2 . The comprehensive diagram reduces the interconnection arbitrariness present in the productive diagrams and calculates the unit cost of both physical and productive internal flows and final products.

- The E Model in the productive diagram is not able to isolate the intercooler (dissipative equipment). Nevertheless, the IC is analyzed together with another productive component. In a comprehensive diagram, the E Model can treat the intercooler. While the H\&S
Model can isolate and treat the entropic term in both diagrams.

- The localized exergy disaggregation was able to isolate the dissipative equipment in the $\mathrm{E}$ Model with less complexity when compared with H\&S Model. However, it cannot treat the residue cost allocation.

- The E Model in the comprehensive diagram presents arbitrariness when using the methods that apply the residue cost distribution ratios since these ratios can be defined in different forms.

E Model residue costs are implicitly allocated to the power and the heat proportionally to the input of the gas turbine and the recovery boiler, respectively. The H\&S Model allocates directly to equipment that increases the entropy of the working fluid and then indirectly through the enthalpic term based on its productive structure definition.

\section{Conclusions and closure}

This work evaluated the influence of the cost formation process on the choice of productive and comprehensive diagrams, as well as the exergy disaggregation for the treatment of dissipative equipment and waste cost allocation, and finally, the localized exergy disaggregation was applied to isolate the dissipative equipment and reduce the complexity. For comparison purposes, the cogeneration system with a regenerative gas turbine, intercooler, and supplementary firing was chosen because it met several demands and challenges of the thermoeconomic analysis.

An important step in defining the cost formation process of a system is the definition of fuel and product, as well as the interconnections between the equipment. Therefore, for the proposed system, the productive diagram showed arbitrariness in the interconnections, due to the junctions and bifurcations since it was possible to elaborate two diagrams with different quantities of fictitious units. Nonetheless, the comprehensive diagram presents only one cost formation process, this is because it uses physical flow to perform the interconnections, giving a physical meaning to the flows. Furthermore, the comprehensive diagram also made it possible to calculate the unit costs of physical and productive flows. However, it is notorious that there is an increase in complexity in the elaboration of the equation system of this diagram, due to the greater number of flows.

The dissipative components were treated in different ways, depending on the thermoeconomic model and diagrams used. For the E Model in the productive diagram, it was necessary to join it with other production equipment. However, information about the cost formation process of these components is lost once they have been merged. Another solution was the physical exergy disaggregation into its enthalpic and entropic terms (H\&S Model). Regardless of the diagram, the disaggregation allowed for defining the function (fuel and product), and isolating all equipment in the system, obtaining more accurate information about cost allocation. The E Model applied to the comprehensive diagram allowed 
the treatment of the intercooler, but it is not possible to define its fuel and product. Another alternative was to use the localized physical exergy disaggregation applied only on the dissipative equipment. This solution allowed defining the fuel and product of the intercooler whilst reducing the complexity to elaborate the cost formation process. Nevertheless, when localized disaggregation was used in combination with $\mathrm{E}$ Model, the methodology could not deal with the waste treatment without the complement of the waste cost allocation methodologies.

The waste cost allocation in H\&S Model is systematically allocated due to the existence of the environment (ENV) as a component and/or unit of the diagram. This way, the residues cost is allocated to all the remaining units and/or components, firstly and directly by means of the entropic term flows and afterward using the enthalpic term flows. Differently from the H\&S Model, when the E Model is applied to the productive diagram, the waste cost allocation is carried out implicitly and proportionally to the fuel of the recovery boiler (RB) and gas turbine (GT). For the comprehensive diagram based on the $\mathrm{E}$ Model, it was necessary to complement the waste cost allocation methodologies, adopting proportionality criteria, which may involve arbitrariness due to different options available, and, thus, the analyst has to decide which one to adopt.

The systematization of the cost formation process of products and associated residues is extremely important for any type of thermoeconomics analysis, whether economic, environmental, or exergetic. Thus, this methodology is applied to any system whose processes are properly designed based on the flows trajectories described in the $(h, s)$ plane $^{[4,50]}$ and any area of thermoeconomics (cost allocation, diagnosis, and optimization), regardless of the cost of whether exergetic, monetary or environmental. Besides systemizing and generalizing, it identifies the cost-formation process of products and associated residues and allows its allocation without arbitrariness. In diagnosis applications, it can provide better methods to detect inefficiencies and their effects on operating systems.

Thusly, the comprehensive diagram with the H\&S Model proved to be the best solution for this case, besides presenting thermodynamic coherence when obtaining exergetic unit costs higher than the unit. It systematized the cost formation process, reduced the arbitrariness level of the interconnections, and isolated the dissipative equipment, in addition to realizing the waste cost allocation with no additional based-ratios methodologies. Nevertheless, this solution presents a considerable increase in complexity due to the rise in the number of flows to be analyzed.

\section{Acknowledgments}

The authors are grateful to the Federal University of Espírito Santo (UFES), the Federal Institute of Espírito Santo (IFES), Coordination for the Improvement of Higher Education Personnel (CAPES), Support Foundation Espírito Santo
Research (FAPES), and Termelétrica Viana S.A. (TEVISA) for financial support.

\section{Conflict of interest}

There are no conflicts to declare.

\section{Supporting information}

Applicable.

\section{Nomenclature}

B Bifurcation

Monetary unit cost [\$/kWh]

Exergy flow $[\mathrm{kW}]$

Specific exergy $\quad[\mathrm{kJ} / \mathrm{kg}]$

Enthalpy flow [kW]

Specific enthalpy $[\mathrm{kJ} / \mathrm{kg}]$

Junction

Exergetic unit cost $[\mathrm{kJ} / \mathrm{kJ}]$

LHV Lower heating value $[\mathrm{kJ} / \mathrm{kg}]$

m Mass flow $[\mathrm{kg} / \mathrm{s}]$

Power $[\mathrm{kW}]$

Heat (exergy) [kW]

Entropy flow $[\mathrm{kW}]$

Specific entropic $[\mathrm{kJ} / \mathrm{kg}]$

Generic thermodynamic magnitude [kW]

Hourly equipment cost $\quad[\$ / \mathrm{h}]$

\section{Subscripts and superscripts}

$\mathrm{CH}$ Chemical

f Fuel

in Inlet

$\mathrm{N}$ Net

out Outlet

U Useful

\section{References}

[1] S. Keshavarzian, M. V. Rocco, F. Gardumi, E. Colombo, Energy Conversion and Management, 2017, 150, 532-544, doi: 10.1016/j.enconman.2017.08.045.

[2] A. Valero, M. A. Lozano, L. Serra, C. Torres, Energy, 1994, 19, 365-381, doi: 10.1016/0360-5442(94)90116-3.

[3] C. Torres, A. Valero, Energies, 2021, 14, 1594, doi: 10.3390/en14061594.

[4] A. Valero, L. Serra, J. Uche, Journal of Energy Resources Technology, 2006, 128, 1-8, doi: 10.1115/1.2134732.

[5] Y. M. El-Sayed, R. A. Gaggioli, Journal of Energy Resources Technology, 1989, 111, 1-7, doi: 10.1115/1.3231396.

[6] M. A. Rosen, International Conference on Energy and Environmental Science, 2008, 1, 136-144.

[7] A. P. Arena, R. Borchiellini, International Journal of Thermal Sciences, 1999, 38, 601-612, doi: 10.1016/S00353159(99)80040-3.

[8] A. Agudelo, A. Valero, C. Torres, Energy, 2012, 45, 634-643, doi: 10.1016/j.energy.2012.07.034.

[9] C. Torres, L. Serra, A. Valero, M. A. Lozano, International 
Mechanical Engineering Congress \& Exposition, 1996, 1, 429436.

[10] J. J. C. S. Santos, M. A. R. Nascimento, E. E. S. Lora, A. M. Martínez Reyes, Proceedings of ECOS, 2008, 2, 641-648.

[11] J. J. C. S. Santos, M. A. R. Nascimento, E. E. S. Lora, Proceedings of ECOS, 2006, 1, 441-448.

[12] A. Lazzaretto, G. Tsatsaronis, Energy, 2006, 31, 1257-1289, doi: 10.1016/j.energy.2005.03.011.

[13] C. A. Frangopoulos, Ph.D. Thesis, Georgia Institute of Technology, 1983.

[14] J. J. C. S. Santos, M. A. R. Nascimento, E. E. S. Lora, A. M. Martínez-Reyes, International Journal of Thermodynamics, 2009, 12, 163-176.

[15] J. J. C. S. Santos, M. A. R. do Nascimento, E. E. S. Lora, J. C. E. Palacio, J. A. M. da Silva, Proceedings of ECOS, 2009, 1, 63-72.

[16] A. B. Lourenço, S. A. Nebra, J. J. C. S. Santos, Proceedings of ECOS, 2014, 1, 1-11.

[17] R. G. Santos, P. R. Faria, I. C. Belisario, M. A. Barone, J. J. C. S. Santos, Proceedings of ENCIT, 2020, 1, 1-9.

[18] R. G. Santos, P. R. Faria, I. C. Belisario, M. A. Barrone, J. J. C. Santos, Revista De Engenharia Térmica, 2020, 19, 63, doi: 10.5380/reterm.v19i2.78618.

[19] P. de Faria, R. dos Santos, J. Santos, M. Barone, B.M.D. Miotto, International Journal of Thermodynamics, 2021, 24, 134 149, doi: 10.5541/ijot.878173.

[20] B. Erlach, L. Serra, A. Valero, Energy Conversion and Management, 1999, 40, 1627-1649, doi: 10.1016/s01968904(99)00057-6.

[21] A. Lazzaretto, A. Macor, Journal of Energy Resources Technology, 1995, 117, 171-178, doi: 10.1115/1.2835337.

[22] V. H. R. Hernández, Ph.D. Thesis, Universidad de Zaragoza, 2005

[23] J. J. Pacheco Ibarra, V. H. Rangel Hernández, A. Zaleta Aguilar, A. Valero, Energy, 2010, 35, 2079-2087, doi: 10.1016/j.energy.2010.01.026.

[24] D. J. R. Orozco, O. J. Venturini, J. C. Escobar Palacio, O. A. del Olmo, Energy, 2017, 123, 20-35, doi: 10.1016/j.energy.2016.12.099.

[25] L. M. de Avellar, M. A. Barone, D. J. R. Orozco, A. B. Lourenço, J. J. C. S. Santos, Proceedings of ENCIT, 2018, 1, 111.

[26] L. M. de Avellar, M. A. Barone, D. J. R. Orozco, A. B. Lourenço, J. J. C. S. Santos, F. R. P. A. Ponce, Proceedings of $E C O S, 2018,1,1-11$.

[27] C. Torres, A. Valero, Energies, 2021, 14, 1594, doi: $10.3390 /$ en 14061594.

[28] C. Torres, A. Valero, V. Rangel, A. Zaleta, Energy, 2008, 33 144-152, doi: 10.1016/j.energy.2007.06.007.

[29] C. A. Frangopoulos, Energy, 1994, 19, 323-342, doi: 10.1016/0360-5442(94)90114-7.

[30] S. M. Seyyedi, H. Ajam, S. Farahat, Energy, 2010, 35, $3474-$ 3482, doi: 10.1016/j.energy.2010.04.047.

[31] L.M H. Denise, T. G E. Vicente, C.H. Sergio, S.P. Martín, L. A. Teresa, L. L. Raúl, Entropy, 2020, 22, 299, doi:

\section{$10.3390 / \mathrm{e} 22030299$}

[32] M. A. Lozano, A. Valero, ASME Book, 1993, 30, 311-320.

[33] M. R. von Spakovsky, Energy, 1994, 19, 343-364, doi: 10.1016/0360-5442(94)90115-5.

[34] G. Tsatsaronis, J. Pisa, Energy, 1994, 19, 287-321, doi: 10.1016/0360-5442(94)90113-9.

[35] J. A. M. da Silva, J. J. C. S. Santos, S. de Oliveira Jr., Proceedings of ECOS, 2010, 1, 1-8.

[36] S. M. Seyyedi, M. Hashemi-Tilehnoee, M. Khaleghi, Arab Journal of Nuclear Sciences and Applications, 2019, 52, 221-233, doi: 10.21608/ajnsa.2018.3875.1092.

[37] X. Luo, J. Hu, J. Zhao, B. Zhang, Y. Chen, S. Mo, Energy, 2014, 72, 459-475, doi: 10.1016/j.energy.2014.05.068.

[38] P. R. Faria, R. G. dos Santos, J. J. C. S. Santos, M. A. Barone, B. M. F. Miotto, Proceedings of ECOS, 2020, 1, 2444-2456.

[39] P. R. Faria, R. G. dos Santos, J. J. Santos, M. A. Barone, B. M. Miotto, International Journal of Thermodynamics, 2021, 24, 134-149, doi: 10.5541/ijot.878173.

[40] R. G. Santos, P. R. Faria, J. J. C. S. Santos, J. A. M. Silva, D. Flórez-Orrego, Energy, 2016, 117, 590-603, doi: 10.1016/j.energy.2016.04.019.

[41] L. R. de Araújo, A. P. Morawski, M. A. Barone, J. L. M. Donatelli, J. J. C. S. Santos, Journal of the Brazilian Society of Mechanical Sciences and Engineering, 2020, 42, 323, doi: 10.1007/s40430-020-02402-6.

[42] C. Frangopoulos, Energy, 1987, 12, 563-571, doi: 10.1016/0360-5442(87)90097-1.

[43] Y. Wang, N. Lior, Desalination, 2007, 214, 306-326, doi: 10.1016/j.desal.2007.01.001.

[44] M. A. Lozano, A. Valero, Energy, 1993, 18, 939-960, doi: 10.1016/0360-5442(93)90006-y.

[45] Engineering Equation Solver - EES, F-Chart Software, 2017.

[46] C. A. Frangopoulos, Encyclopedia of Life Support Systems, 2009, 2, 1-454.

[47] M. Modesto, S. A. Nebra, Energy, 2006, 31, 3261-3277, doi: 10.1016/j.energy.2006.03.032.

[48] M. A. Barone, R. G. dos Santos, P. R. de Faria, R. A. Lorenzoni, A. B. Lourenço, J. J. C. S. Santos, Proceedings of ECOS, 2021, 1, 1-12.

[49] L. M. Serra, Ph.D. Thesis, Universidad de Zaragoza, Zaragoza, Spain, 1994.

[50] A. Valero, J. Royo, M. A. Lozano, Second Law Analysis for Process and Energy Engineering, 1995, 1, 99-112.

[51] A. S. Dogonchi, S. M. Seyyedi, Journal of Dynamical and Control Systems, 2018, 1, 28-36.

[52] R. B. Evans, Energy, 1980, 5, 804-821, doi: 10.1016/03605442(80)90098-5. 


\section{Author Information}

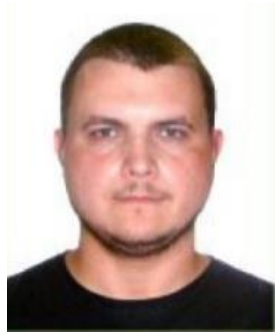

Dr. Marcelo A. Barone received his Ph.D. degree in Mechanical Engineering from Federal University of Espirito Santo in 2021. The doctoral thesis title is "Comprehensive Diagram and Exergy Disaggregation: A Proposal for Generalized Systematization of Thermoeconomic Modeling". His research interest is in exergy and thermoeconomics.

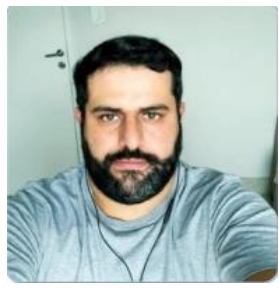

Mr. Rodrigo G. dos Santos, currently pursuing his Ph.D.degree under the guidance of Prof. José Joaquim C. S. Santos, the Department of Mechanical Engineering, Federal University of Espírito Santo, Brazil, since 2020. Mr. RODRIGO GUEDES DOS SANTOS received his M. Sc. Degree from Federal University of Espirito Santo in 2015. Rodrigo GUEDES DOS SANTOS is currently working as assistant Professor at the Department of Mechanical Engineering, Federal Institute of Espírito Santo - IFES, Vitória, Brazil. His main research interest is in exergy and thermoeconomics. He has published more than 18 research documents (articles and papers) for well reputed conferences and journals.

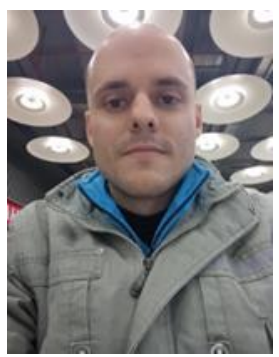

Mr. Pedro R. de Faria, currently pursuing his Ph.D. degree under the guidance of Prof. José Joaquim C. S. Santos, the Department of Mechanical Engineering, Federal University of Espírito Santo, Brazil. Mr. PEDRO ROSSETO DE FARIA received his $M$. Sc. Degree from Federal University of Espírito Santo in 2014. PEDRO ROSSETO DE FARIA is currently working as assistant Professor at the Federal Institute of Espírito Santo - IFES, Cariacica, Brazil. His main research interest is in exergy and thermoeconomics. He has published more than 18 research documents (articles and papers) for well reputed conferences and journals.

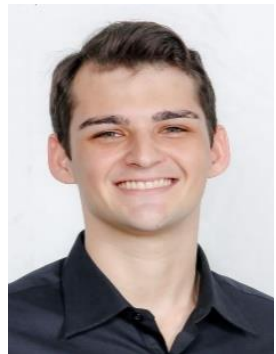

Mr Raphael Amorim Lorenzoni is currently working as research scholar under the supervision of Prof. José Conceição Soares Santos, Department of Mechanical Engineering, Federal University of Espírito Santo, since 2018. Mr Lorenzoni received his M. Sc. Degree
(Thermal Sciences) from Federal University of Espírito Santo in 2017, where as well graduated in Mechanical Engineering (Materials Corrosion). His main research interests are thermodynamics, thermoeconomics, and diagnosis. He has published more than 4 research articles in international journals.

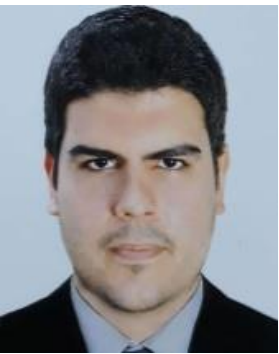

Prof Dr Atilio B Lourenço is an assistant professor at the Department of Mechanical Engineering, Federal University of Espirito Santo, Brazil. He received his $P h D$ degree in Energy from Federal University of ABC, Brazil. His research interest is in exergy, exergoeconomic and exergoenvironmental analysis of energy conversion systems.

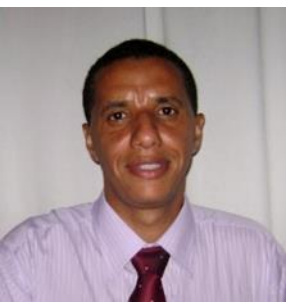

Prof. (Dr.) José Joaquim C. S. Santos is currently working as Researcher and Professor in the Department of Mechanical Engineering, Federal University of Espirito Santo, Brazil. Prof. Santos received his $P h$. D. degree from Federal University of Itajubá, Brazil, in 2009. He has been continuously engaged in the research filed of Thermoeconomics and Exergy Analysis for the last 20 years. His other research interests are: Thermal Power Generation, Cogeneration, Thermal System Repowering and Waste Heat Recovery, Concentrating Solar Power, Geothermal Power and Desalination. He has published more than 130 research documents (articles, papers and chapters) for well reputed conferences, journals and books (respectively).

Publisher's Note: Engineered Science Publisher remains neutral with regard to jurisdictional claims in published maps and institutional affiliations. 